\title{
Pharmacokinetic Concentration Specimen Condition
}

National Cancer Institute

\section{Source}

National Cancer Institute. Pharmacokinetic Concentration Specimen Condition. NCI

Thesaurus. Code C87968.

A characteristic that refers to the physical and org anoleptic state of a biospecimen used for a pharmacokinetic concentration assessment. 